\title{
The color removal of dye wastewater by magnesium chloride/red mud (MRM) from aqueous solution
}

\author{
Qi Wang ${ }^{\mathrm{a}}$, Zhaokun Luan ${ }^{\mathrm{a}, *}$, Ning Wei ${ }^{\mathrm{a}}$, Jin Li ${ }^{\mathrm{a}}$, Chengxi Liu ${ }^{\mathrm{b}}$ \\ a State Key Laboratory of Environmental Aquatic Chemistry, Research Center for Eco-Environmental Sciences, Chinese Academy of Sciences, P.O. Box 2871, Beijing 100085, China \\ ${ }^{\mathrm{b}}$ School of Chemical and Environmental Engineering, China University of Mining and Technology, Beijing 100083, China
}

\section{A R T I C L E I N F O}

\section{Article history:}

Received 31 December 2008

Received in revised form 4 April 2009

Accepted 7 May 2009

Available online 14 May 2009

\section{Keywords:}

Magnesium chloride

Red mud

Dye wastewater

Solid waste

Decolorization

\begin{abstract}
A B S T R A C T
In this study, the $\mathrm{MgCl}_{2} /$ red mud system (MRM) was used to investigate the color removal efficiency of dye solutions. Parameters such as the effect of the dosage of red mud (RM) and $\mathrm{MgCl}_{2}$ have been studied. The effect of $\mathrm{pH}$ on the conversion rate of $\mathrm{Mg}^{2+}$ has also been studied. The color removal efficiency of MRM was compared with that of PAC/RM and PAC/NaOH. Meanwhile, the color removal efficiency of RM was compared with that of $\mathrm{NaOH}$. The results show that the MRM system can remove more than $98 \%$ of the coloring material at a dosage of $25 \mathrm{~g} \mathrm{RM} / \mathrm{L}$ dye solution and a volume of $1.5 \mathrm{~mL} \mathrm{MgCl}_{2} / \mathrm{L}$ dye solution in the decolorization process of reactive dye, acid dye and direct dye. The color removal efficiency was better than PAC/RM and PAC/NaOH system. The adsorption data have been analyzed using Langmuir and Freundlich isotherms. The results indicated that both models provide the best correlation of the experimental data. The decolorization mechanism of MRM was discussed, too. The MRM system was a viable alternative to some of the more conventional forms of chemical treatment of dye solutions and also provided another way to make use of industrial waste red mud.
\end{abstract}

(c) 2009 Elsevier B.V. All rights reserved.

\section{Introduction}

At present, large amounts of highly colored wastewater are discharged from textile, printing, paper, and leather industries which use many kinds of artificial composite dyes. These dye-containing industrial wastewaters discharged into streams and river constitutes one of the major sources of water pollution. Color waters are objectionable on aesthetic grounds for drinking and other agricultural purposes. Color affects the nature of the water, inhibits sunlight penetration into the stream, and reduces the photosynthetic action. In addition, some dyes are either toxic or mutagenic and carcinogenic [1]. So, these wastes must be treated prior to discharge in order to comply with the environmental protection laws for the receiving waters. In the past years, several investigations have been carried out to explore the treatment operations of color wastewater, such as biological treatment. However, the conventional biological treatment processes frequently used to treat textile effluents are generally efficient for biochemical oxygen demand (BOD) and suspended solids (SS) removal, and are largely ineffective for removing color from the waste [2,3], due to most dyes are stable to light and oxidation [4]. Thus, treated waste effluents may contain appreciable amounts of color when discharged. Now, the treatment technologies recommended meeting color removal requirements

\footnotetext{
* Corresponding author. Tel.: +86 10 62849150; fax: +86 1062849198. E-mail address: wq020704@126.com (Z. Luan).
}

are physical-chemical treatment operations, including adsorption [5-11], ozonation [12,13] and chemical precipitation [14-16]. Each has its merits and limitations in application.

In the decolorization process by chemical precipitation, the coagulant is used and produces flocs together with dye stuffs. The flocs are then separated from the aqueous solution by means of physical sedimentation. The well-known conventional coagulants such as alum, $\mathrm{PAC}, \mathrm{FeSO}_{4}$ and lime are widely used in the industrial wastewater treatment. In recent years, the study on $\mathrm{MgCl}_{2}$ has been done on the removal of color from textile waste effluents [17,18]. Comparing with those conventional chemical coagulants, the magnesium salts have been shown to be an effective alternative and can enhance removal efficiency of impurities or pollutants in the treatment of wastewater $[19,20]$. In addition, one of the most attractive characteristics of magnesium salts is recycled through the process. This recoverability may significantly reduce the chemical costs and especially may reduce the pollution.

The adsorption process is another attractive alternative treatment process if the adsorbent is inexpensive and readily available. Activate carbon is the most powerful and common adsorbent and has been used successfully. But the high cost in the preparation of activated carbon restricts its use in the industrial wastewater treatment, especially in the developing countries. In recent years, many studies have been done on the non-conventional and economic adsorbents [21], especially those researches on making use of industrial solid waste. Using an industrial solid waste for the treatment of wastewaters from another industry could be helpful 
Magnesium powder

$$
\downarrow \begin{aligned}
& \text { Ground and sieved } \\
& \text { The particles below } 180 \mu \mathrm{m}
\end{aligned}
$$

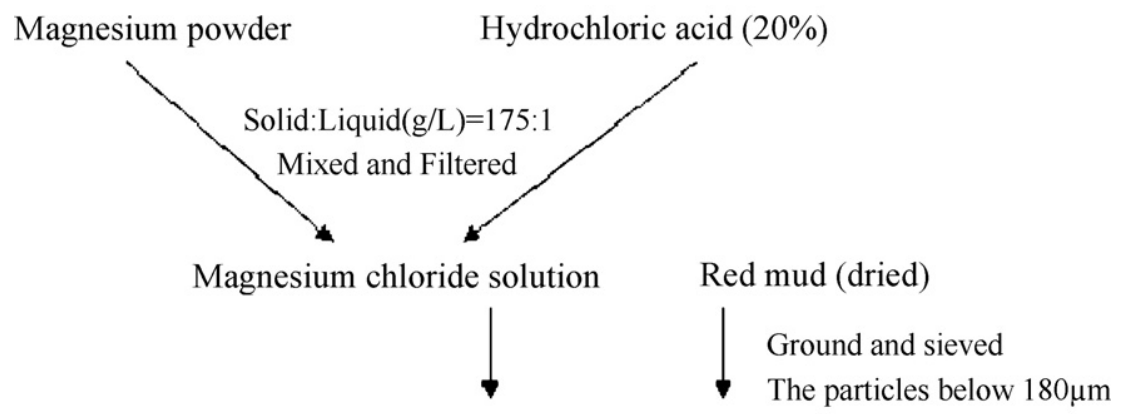

Dye solutions

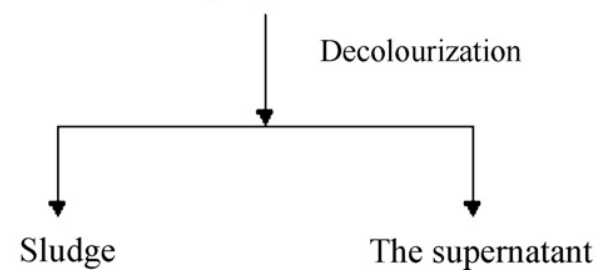

Fig. 1. The preparation and treatment process of dye solutions by MRM.

not only to the economy, but also to solve the solid waste disposal problem.

Red mud (RM) is a solid waste residue formed after the caustic digestion of bauxite ores during the production of aluminum. For every ton of aluminum produced, approximately one to two tons (dry weight) of bauxite residues are generated. Each year, about 90 million tons of red mud are produced globally [22] and nearly 20 million tons of red mud are created annually in China. Red mud is a highly alkaline waste material with $\mathrm{pH} 10-12.5$. Due to the alkaline nature and the chemical and mineralogical species present in red mud, this solid waste causes a significant impact on the environment and proper disposal of waste red mud presents a huge challenge where aluminum industries are installed. In the past years, several investigations have been carried out to explore the applicability of red mud for dye removal from wastewater. Namasivayam et al. [4,23] reported high color removal efficiency of dye wastewater using red mud as an adsorbent. Utilization of industrial wastes for another waste treatment produces many benefits in terms of economy and environment.

The present paper is aimed to investigate and develop a kind of novel and economical method for color removal from aqueous solution using $\mathrm{MgCl}_{2}$ and red mud system (MRM). The preparation procedure of MRM system and treatment process of dye solutions by MRM was depicted as Fig. 1. One kind of reactive dyes, acid dyes and direct dyes were chosen for experiment. Optimum conditions of decolorization such as the dosage of red mud and $\mathrm{MgCl}_{2}$ were also determined. The effectiveness of MRM was compared with that of polyaluminium chloride (PAC)/RM and $\mathrm{PAC} / \mathrm{NaOH}$. The color removal mechanism of MRM for the dye wastes was also studied.

\section{Materials and methods}

\subsection{Materials}

Magnesium powder (92\%) and the dyes were obtained from Haicheng Chemicals Co., Ltd., China. Hydrochloric acid (20\%) and polyaluminium chloride (PAC) were supplied from Tianjin, China. These were of industrial grade. The red mud (sintering process)
Table 1

The chemical composition ( $\mathrm{wt} \%$ ) of the mud.

\begin{tabular}{lr}
\hline Constituent & wt\% \\
\hline $\mathrm{Na}_{2} \mathrm{O}$ & 5.94 \\
$\mathrm{Fe}_{2} \mathrm{O}_{3}$ & 21.02 \\
$\mathrm{Al}_{2} \mathrm{O}_{3}$ & 10.89 \\
$\mathrm{CaO}+\mathrm{MgO}$ & 16.79 \\
$\mathrm{SiO}_{2}$ & 13.39 \\
$\mathrm{TiO}_{2}$ & 13.98 \\
Loss on ignition & 16.92 \\
\hline
\end{tabular}

used in this work was supplied by the Shandong Aluminum Corp., Ltd., China. $\mathrm{NaOH}$ was of reagent grade.

The characteristics of red mud were shown in Table 1. Chemical analysis reveals that red mud contains mainly silica, aluminum, iron, calcium, titanium, as well as an array of minor constituents, namely: $\mathrm{Na}, \mathrm{K}, \mathrm{Cr}, \mathrm{V}, \mathrm{Ni}, \mathrm{Ba}, \mathrm{Cu}, \mathrm{Mn}, \mathrm{Pb}$, and $\mathrm{Zn}$. Red mud is a very fine material in terms of particle size distribution. Fig. 2 shows SEM

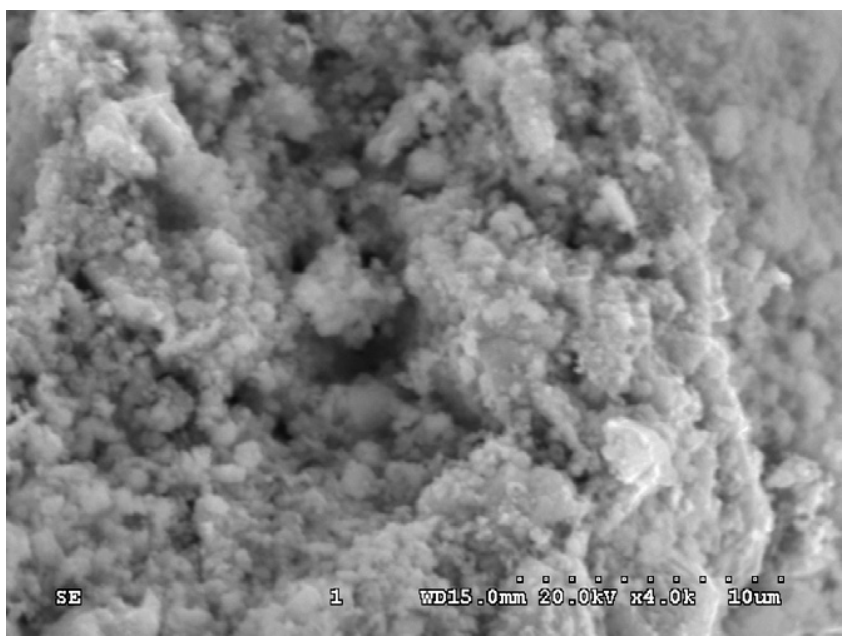

Fig. 2. SEM photos of red mud. 
Table 2

Dye characteristics.

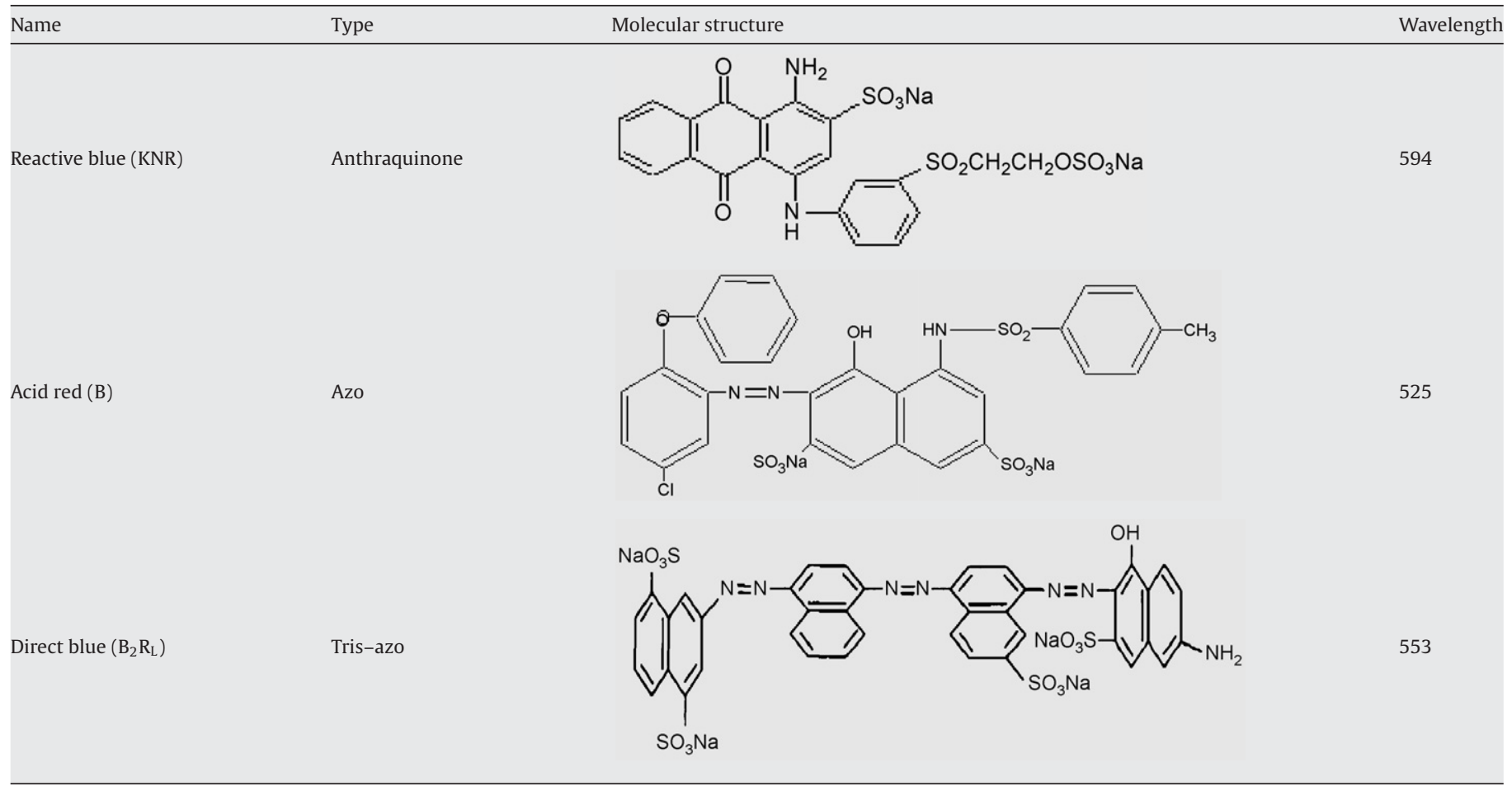

photos of red mud. Red mud contains various particles with different size and shape. Some crystals can also be found in the sample. In addition, the red mud also presents porous surface and has a larger surface area. It can be seen from Fig. 3 that the surface area of the sample, was determined by the BET nitrogen gas sorption method using an accelerated surface area and porosimetry (ASAP 2000) from Micromeritics Co., USA, is $40 \mathrm{~m}^{2} / \mathrm{g}$. X-ray diffraction(XRD) patterns of the sample (a precipitate produced in the $\mathrm{pH}$ range from 12 to 13 in $\mathrm{MgCl}_{2}$ solutions) was obtained with a Rigaku Dmax-RB diffractometer using $\mathrm{Cu} K \alpha$ radiation at $40 \mathrm{kV}$ and $40 \mathrm{~mA}$ over the $2 \theta$ range of $10-80^{\circ}$.

\subsection{Decolorization experiments}

Laboratory tests were conducted on three different synthetic dye wastes, which were prepared by adding $0.1 \mathrm{~g}$ of the dyestuff to $1 \mathrm{~L}$ of distilled water. The synthetic wastes were studied in order to

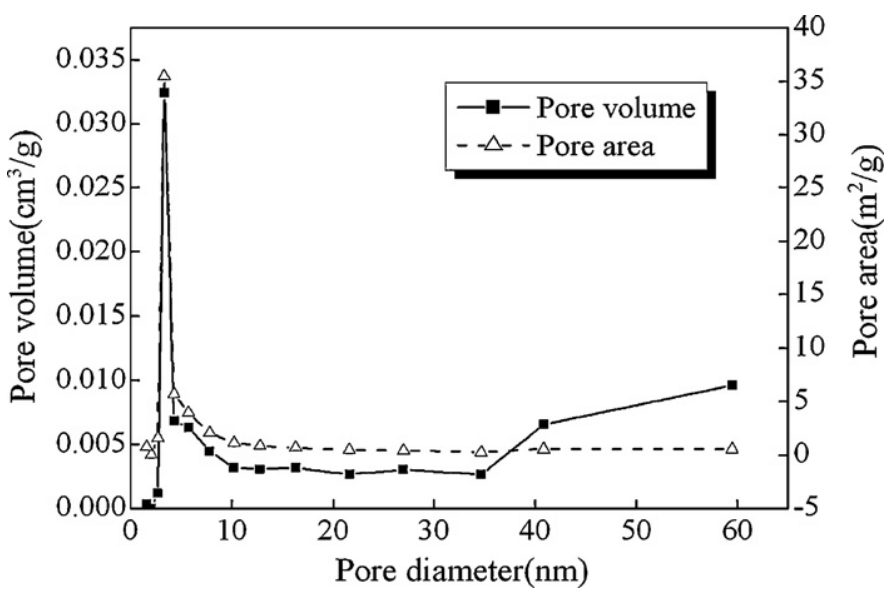

Fig. 3. Differential and cumulative pore size distribution curves for red mud determine the effectiveness of MRM in removing various types of dyestuff. It was hoped that the use of pure dye solutions would make it possible to obtain information about the color removal efficiency of reagent for different types of dyes. The name, type, molecular structure and the wavelength of maximum absorbance wavelength $\left(\lambda_{\max }\right)$ of the three dyes selected for this study are shown in Table 2 .

The optimum $\mathrm{pH}$ value and optimum dosages of reactants required for color removal were determined by a jar test procedure. The $\mathrm{pH}$ of the solution was measured with a $\mathrm{pH}$ meter (ORION 710A). Six $500 \mathrm{~mL}$ beakers, containing $200 \mathrm{~mL}$ of dye waste, were placed on a six-position mechanical stirrer. The reagent and the waste were mixed for $5 \mathrm{~min}$ at $150 \mathrm{rpm}$. There then followed a 20-min period of slow stirring at $60 \mathrm{rpm}$ and $30 \mathrm{~min}$ of sedimentation. An aliquot of supernatant was pipetted from each jar and then filtrated to obtain clear liquid. Then, the $\mathrm{pH}$ of the liquid was adjusted to about 7.0 using $0.1 \mathrm{M} \mathrm{HNO}_{3}$ solution. The absorbance of the liquid was measured and the characteristic wavelength for each dye was determined by running a scan of the dye on a spectrophotometer (HACH DR-5000). Percentage of color removal was calculated by comparing the absorbance values for the waste after treatment to the absorbance value for the original dye waste. Distilled water served as a reference. Langmuir and Freundlich isotherms were employed to evaluate the equilibrium data.

\section{Results and discussion}

\subsection{Effect of the dosage of RM}

The dosage of RM plays an important role in the whole adsorption process. The removal of dyes from a $0.1 \mathrm{~g} / \mathrm{L}$ dye solutions by MRM system has been studied by varying the dosage of RM in the dye solutions. The amount of $\mathrm{MgCl}_{2}$ is kept at $1.5 \mathrm{~mL} / \mathrm{L}$ dye solutions. The absorbance values of dye solutions after adjusting the final $\mathrm{pH}$ to 7.0 because that the $\mathrm{pH}$, varies with the dosage of RM, could 


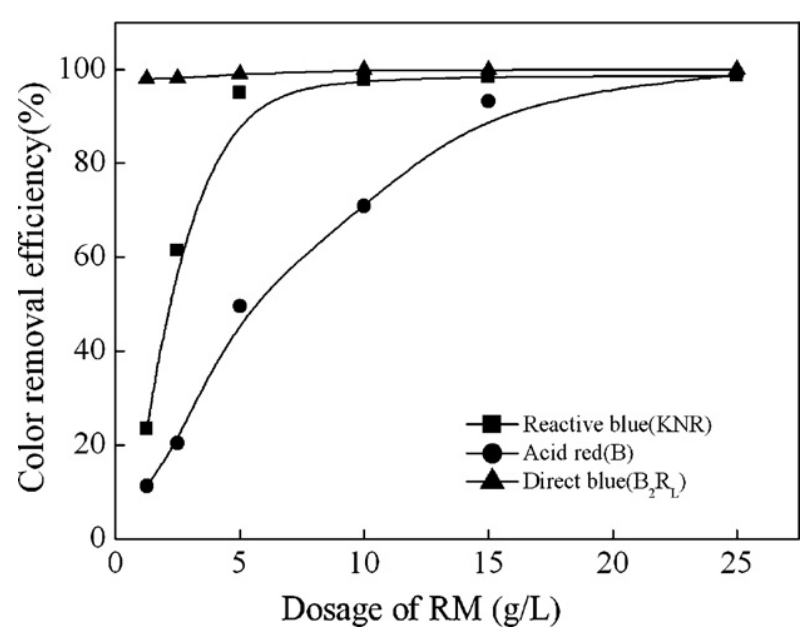

Fig. 4. Effect of dosage of RM on the color removal efficiency.

affect the molecular structure of the dyes, which would change the absorbance of the solutions [24].

The color removal efficiency of dye solutions over a broad range of dosage of RM is shown in Fig. 4. As shown, the color removal efficiency increased with increasing the amount of RM in the dosage range $1.25-25 \mathrm{~g} / \mathrm{L}$. The color removal efficiency of direct blue $\left(\mathrm{B}_{2} \mathrm{R}_{\mathrm{L}}\right)$ was not significantly changed and that of reactive blue (KNR) and acid red (B) increased from 23.5 to 98.7 and from 11.35 to 98.8 , respectively, when the dosage of RM was increased from 1.25 to $25 \mathrm{~g}$. The reason for high removal efficiency is that the addition of $\mathrm{RM}$ changes the $\mathrm{pH}$ of the dye solutions. The $\mathrm{pH}$ of the dye solutions is above 12 when the addition of RM amounted to $25 \mathrm{~g} / \mathrm{L}$ dye solution. When the $\mathrm{pH}$ value is higher than 12.0 , most of the magnesium ions are converted into precipitable hydroxide, which is consistent with Tan et al. [18]. Leentvaar and Rebhun [25] reported that the $\mathrm{Mg}(\mathrm{OH})_{2}$ precipitate acts through an adsorptive coagulating mechanism and its structure provided a large adsorptive surface area and its positive electrostatic surface charge enabled it to act as a powerful and efficient coagulant.

\subsection{Effect of the $\mathrm{MgCl}_{2}$ dosage on color removal}

The effect of $\mathrm{MgCl}_{2}$ dosage on the color removal of three dye solutions was investigated. The dosage of $\mathrm{MgCl}_{2}$ was increased from

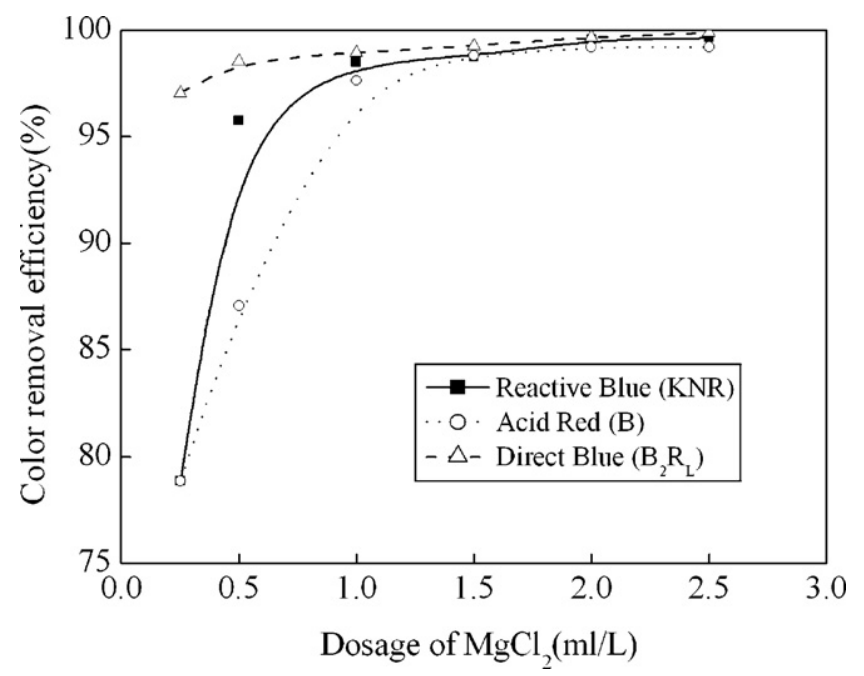

Fig. 5. Effect of dosage of $\mathrm{MgCl}_{2}$ on the color removal efficiency.

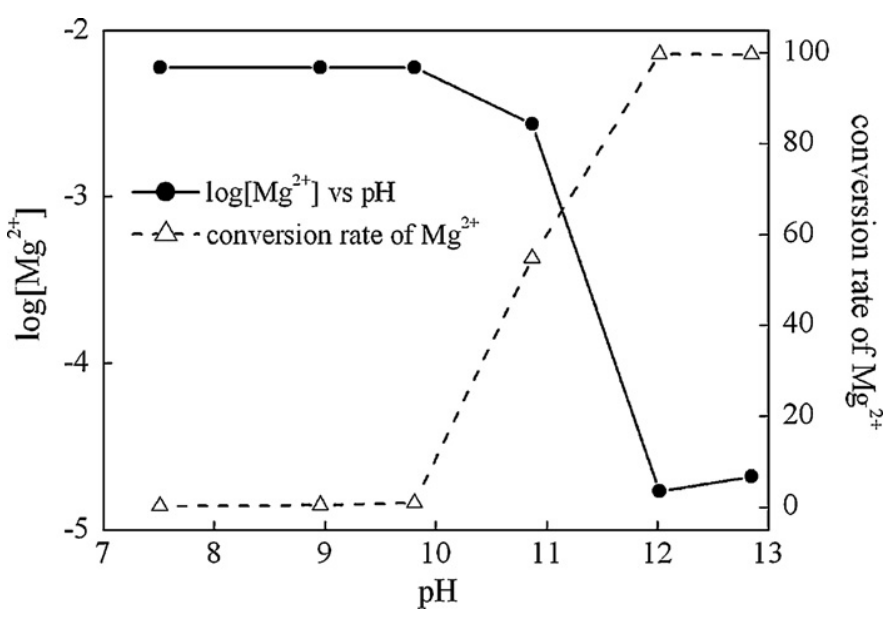

Fig. 6. Effect of $\mathrm{pH}$ on the conversion of $\mathrm{Mg}^{2+}$.

0.25 to $2.5 \mathrm{~mL} / \mathrm{L}$ with a fixed amount of RM $(25 \mathrm{~g} / \mathrm{L})$ dosage. The results were shown in Fig. 5. It is evident that dye removal gradually improved with increasing $\mathrm{MgCl}_{2}$ dosage except direct blue $\left(\mathrm{B}_{2} \mathrm{R}_{\mathrm{L}}\right)$. About $99 \%$ of decolorization was observed when $\mathrm{MgCl}_{2}$ dosage was above $1.5 \mathrm{~mL} / \mathrm{L}$. But further increase in the $\mathrm{MgCl}_{2}$ dosage does not produce higher removal rate, which due to almost all the dyes have been removed at this stage. The presence of excessive $\mathrm{MgCl}_{2}$ will form too much flocs which may result in longer settling time. Previous studies for dye wastewater treatment showed similar results [18].

\subsection{The effect of $\mathrm{pH}$ on the conversion of $\mathrm{Mg}^{2+}$}

The effect of $\mathrm{pH}$ on the conversion of $\mathrm{Mg}^{2+}$ was investigated. Fig. 6 is a plot of the $\log \left[\mathrm{Mg}^{2+}\right]$ and the conversion rate of $\mathrm{Mg}^{2+}$ versus the $\mathrm{pH}$ of the solution. It shows that $\mathrm{Mg}^{2+}$ is not transformed until a $\mathrm{pH}$ of 9.5 and that the conversion rate of $\mathrm{Mg}^{2+}$ increases with increasing $\mathrm{pH}$ value of the solution from 9.5 to 12.8 . This is probably because magnesium ions were transformed into hydroxide. The solubility of $\mathrm{Mg}(\mathrm{OH})_{2}$ is given by

$K \mathrm{sp}=\left[\mathrm{Mg}^{2+}\right]\left[\mathrm{OH}^{-}\right]^{2}$

where Ksp is the dissociation constant of the hydroxide. Increase in $\mathrm{Mg}^{2+}$ ion or $\mathrm{OH}^{-}$ion concentration beyond the Ksp value favors the formation of $\mathrm{Mg}(\mathrm{OH})_{2}$. When the $\mathrm{pH}$ value falls in the range from 9.5 to $12.8, \mathrm{Mg}(\mathrm{OH})_{2}$ occurs and the conversion rate of $\mathrm{Mg}^{2+}$ increases gradually.

\subsection{The comparison of RM with $\mathrm{NaOH}$}

Figs. 7-9 show the plots of the rate of removal of three dye solutions versus the $\mathrm{pH}$ values for different coagulants. It is reported [26-29] previously that RM is believed as a promising material for coagulant production, due to high contents of $\mathrm{Fe}$ and $\mathrm{Al}$ in red mud and porous surface. Meanwhile, it is also found that $\mathrm{NaOH}$ is capable of serving as a coagulant and can give a certain degree of color removal effectiveness in the decolorization process. It can be seen from Figs. 7-9 that the color removal efficiency of three dye solutions increases with $\mathrm{pH}$ increase. Figures show that red mud is more effective in a higher $\mathrm{pH}$ range. The color removal efficiency of reactive blue (KNR) waste and direct blue $\left(B_{2} R_{L}\right)$ wastewater are higher than acid red (B). The results above also suggest that the high color removal efficiency of dye solutions require the less volume of $\mathrm{MgCl}_{2}$ when $\mathrm{RM}$ is chosen in the decolorization process. 


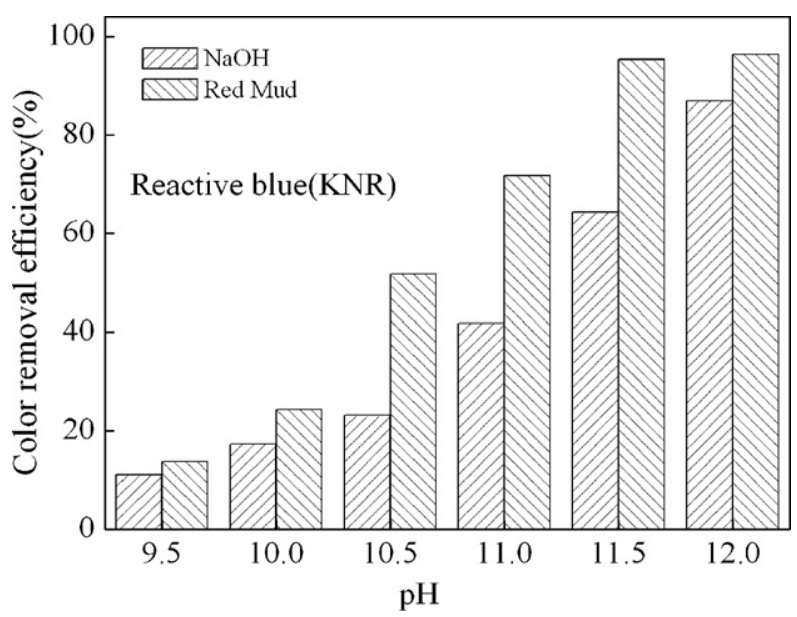

Fig. 7. Color removal efficiency of reactive blue (KNR) by $\mathrm{RM}$ and $\mathrm{NaOH}$ as function of $\mathrm{pH}$.

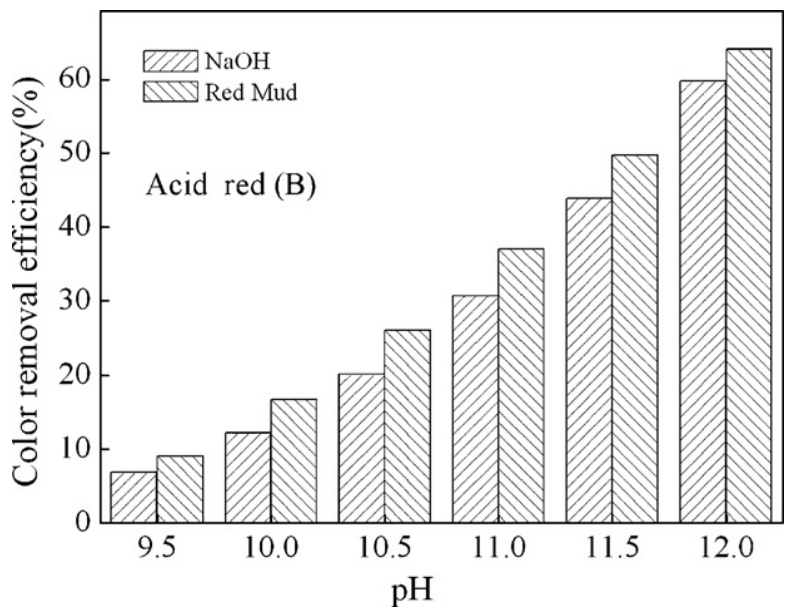

Fig. 8. Color removal efficiency of acid red (B) by $\mathrm{RM}$ and $\mathrm{NaOH}$ as function of $\mathrm{pH}$.

\subsection{Comparing the color removal efficiency of MRM with that of $\mathrm{PAC} / \mathrm{RM}$ and $\mathrm{PAC} / \mathrm{NaOH}$}

Fig. 10 shows the plot of the efficiency of color removal of the wastes versus the dosage of different coagulants. When PAC is used as a coagulant, the $\mathrm{pH}$ of the water is depressed because of the

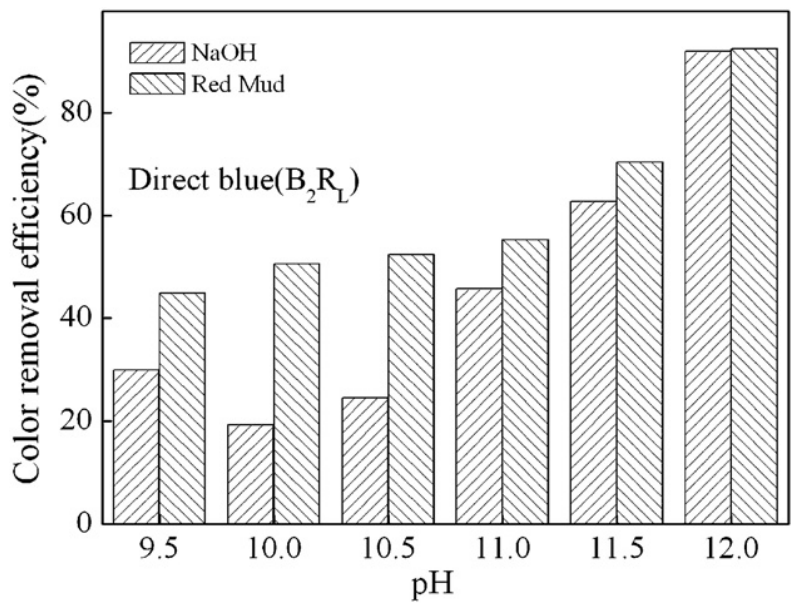

Fig. 9. Color removal efficiency of direct blue $\left(\mathrm{B}_{2} \mathrm{R}_{\mathrm{L}}\right)$ by $\mathrm{RM}$ and $\mathrm{NaOH}$ as function of $\mathrm{pH}$.
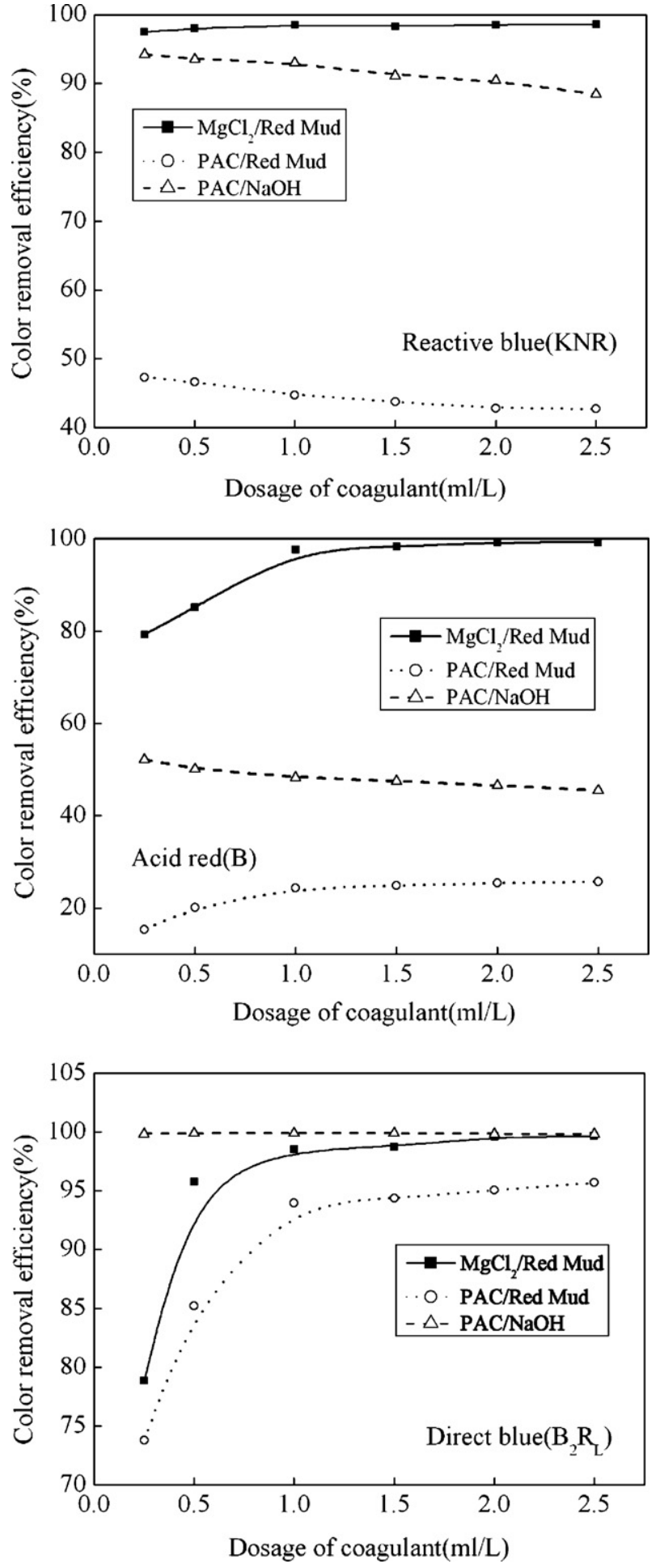

Fig. 10. Color removal efficiency by different coagulants as a function of dosage.

presence of excess hydrogen ions. So, $\mathrm{RM}$ or $\mathrm{NaOH}$ is added to the wastes to maintain a $\mathrm{pH}$ above 12.0 during treatment. It is evident that MRM is more effective for the reactive dye, acid dye and direct dye among the coagulants tested. It can be seen from Fig. 10 that the color removal efficiencies of reactive and acid dye solutions are lower when either PAC/RM or $\mathrm{PAC} / \mathrm{NaOH}$ is chosen. The reason for that is the optimum color removal $\mathrm{pH}$ range for PAC was previously reported to be 5.5-6.5 [30]. The color removal rate is worse even if the PAC is combined with RM. 


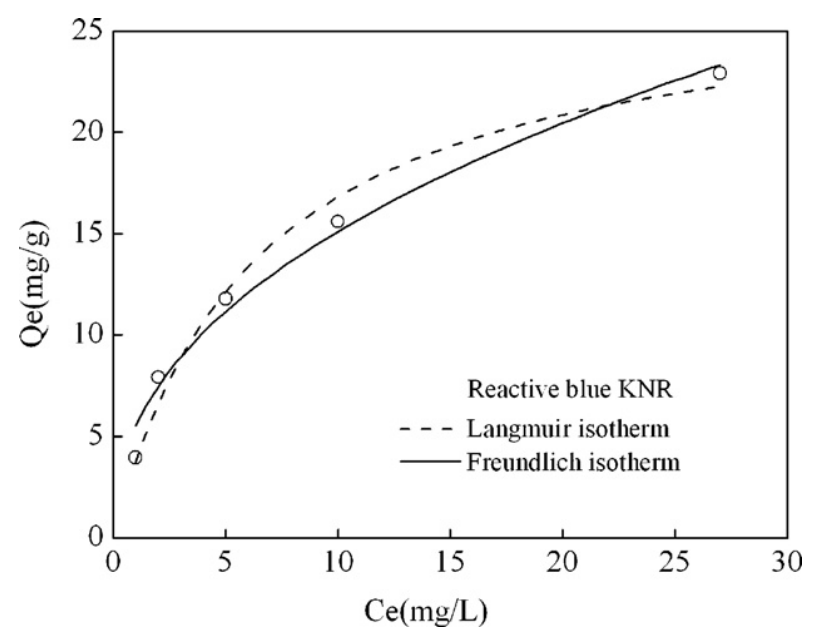

Fig. 11. Isotherm equation plots for the adsorption of reactive blue (KNR) onto RM.

It is well known that the range of $\mathrm{pH}$ of actual wastes, collected at textile and dyeing mills, usually is from 9.0 to 11.0. Such a waste could be extremely difficult to treat with some common coagulants directly, such as PAC, unless the $\mathrm{pH}$ is reduced firstly. However, these wastes should be ideally suited to treatment with MRM system. Because the $\mathrm{pH}$ value would be increased after adding less dosage of RM to the dye solutions and the better color removal efficiency could be obtained if $\mathrm{MgCl}_{2}$ is chosen for coagulant.

\subsection{Adsorption isotherms}

The equilibrium adsorption isotherm is important in the design of adsorption systems. Two important isotherms are selected in this study, the Langmuir and Freundlich isotherms.

The Langmuir adsorption isotherm assumes that adsorption takes place at specific homogeneous sites within the adsorbent and has found successful application to many sorption processes of monolayer adsorption. The Langmuir equation was applied for the adsorption equilibrium as follows:

$\frac{C_{\mathrm{e}}}{Q_{\mathrm{e}}}=\frac{1}{Q_{\mathrm{m}} K}+\frac{C_{\mathrm{e}}}{Q_{\mathrm{m}}}$

where $Q_{e}$ is the adsorbed amount of the dye under equilibrium $(\mathrm{mg} / \mathrm{g}), C_{\mathrm{e}}$ is the equilibrium concentration of the dye in solution $(\mathrm{mg} / \mathrm{L}), Q_{\mathrm{m}}$ is the monolayer adsorption capacity $(\mathrm{mg} / \mathrm{g})$ and $K(\mathrm{~L} / \mathrm{mg})$ is the constant related to the free energy of adsorption.

The Freundlich isotherm is an empirical equation employed to describe heterogeneous systems. The Freundlich equation is

$Q_{\mathrm{e}}=K_{\mathrm{f}} C_{\mathrm{e}}^{1 / n}$

where $K_{\mathrm{f}}$ and $n$ are Freundlich adsorption isotherm constants, being indicative of the extent of the adsorption and the degree of nonlinearity between solution concentration and adsorption, respectively.

The experimental data of three dyes at $\mathrm{pH} 12$ and the two adsorption isotherms fitted to them are shown in Figs. 11-13. The correlation coefficient $R^{2}$ from two isotherms obtained from nonlinear regression are presented in Table 3. The linear plots of $C_{\mathrm{e}} / Q_{\mathrm{e}}$

Table 3

Adsorption isotherm models.

\begin{tabular}{lll}
\hline Dyes & $R^{2}$ & \\
\cline { 2 - 3 } & Freundlich isotherm & Langmuir isotherm \\
\hline Reactive blue (KNR) & 0.9838 & 0.9819 \\
Acid red $(\mathrm{B})$ & 0.9496 & 0.8427 \\
Direct blue $\left(\mathrm{B}_{2} \mathrm{R}_{\mathrm{L}}\right)$ & 0.9544 & 0.9391 \\
\hline
\end{tabular}

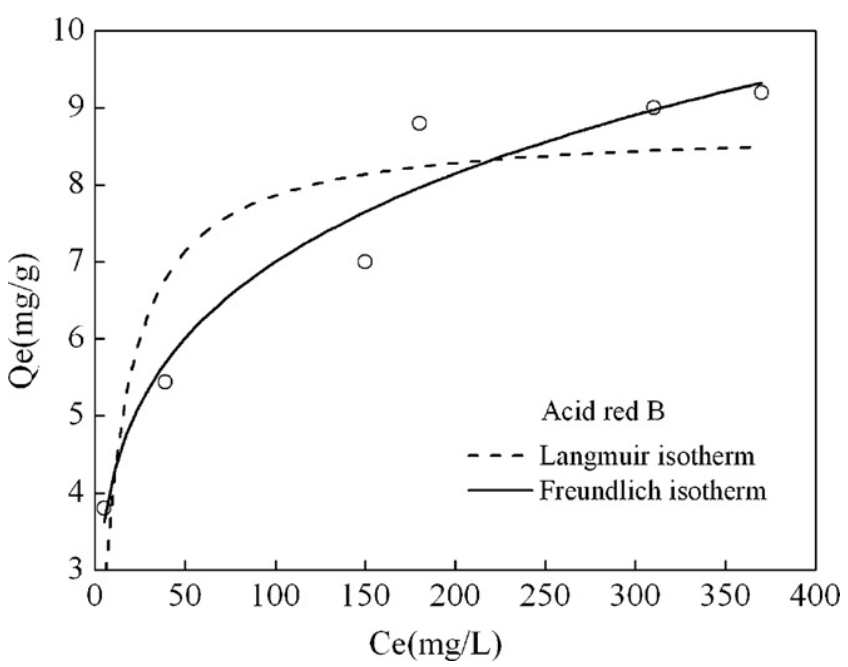

Fig. 12. Isotherm equation plots for the adsorption of acid red (B) onto RM.

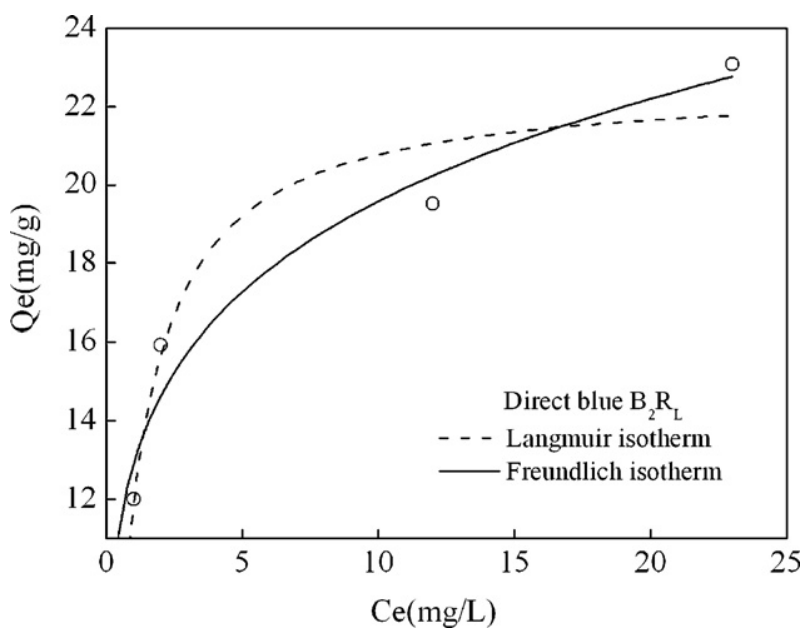

Fig. 13. Isotherm equation plots for the adsorption of direct blue $\left(B_{2} R_{L}\right)$ onto RM.

versus $C_{\mathrm{e}}$ were obtained for three different dyes, indicating that adsorption of dyes on MRM obeyed the Langmuir isotherm model. Plots fitted by the Langmuir equation for three dyes were presented in Fig. 14. Adsorption capacity of the MRM was found to

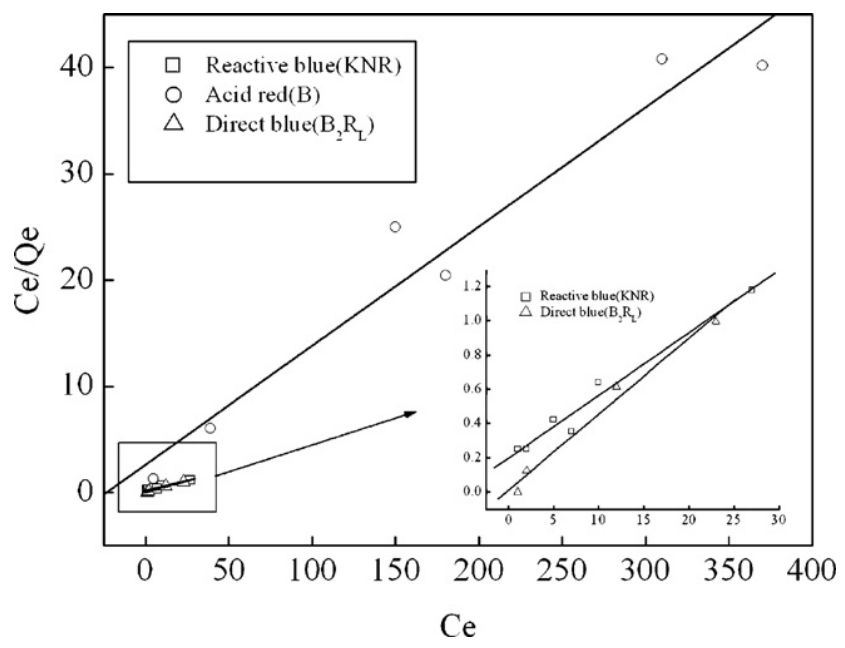

Fig. 14. Langmuir adsorption linear plots for dyes adsorption on RM. 


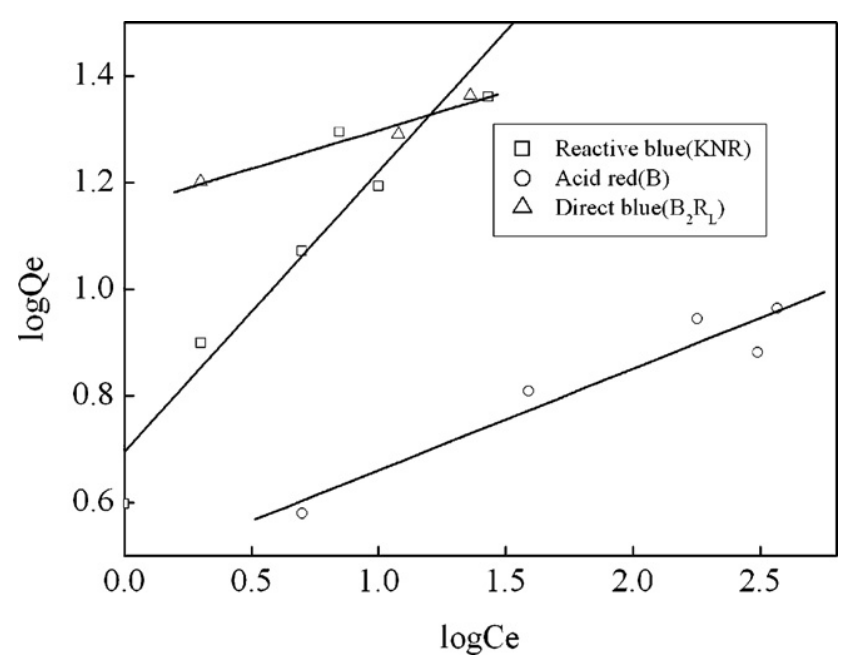

Fig. 15. Freundlich adsorption linear plots for dyes adsorption on RM.

be $27.405,8.921$ and $22.563 \mathrm{mg} / \mathrm{g}$ for reactive blue (KNR), acid red (B) and direct blue $\left(B_{2} R_{L}\right)$, respectively. The linear plots of $\log Q_{e}$ versus $\log C_{\mathrm{e}}$ were obtained for three different dyes, indicating that adsorption of dyes on MRM obeyed the Freundlich isotherm model, too. Plots fitted by the Freundlich equation for three dyes were presented in Fig. 15. The model parameters obtained from linear regression are presented in Table 4 . In addition, it can be seen from Table 4, Figs. 14 and 15 that the Langmuir model describes better reactive blue (KNR) and direct blue $\left(B_{2} R_{L}\right)$ than the Freundlich model and acid red (B) is adequately described by the Freundlich model.

\subsection{Spectral analysis and initial investigation of the color removal mechanism of MRM}

\subsubsection{Spectral analysis of treated and untreated wastes}

Reactive blue (KNR) waste, acid red (B) waste and direct blue $\left(B_{2} R_{L}\right)$ waste are selected for this experiment. The spectrum analysis is made on untreated wastewater and wastewater treated with a combination of $1.5 \mathrm{~mL} / \mathrm{L}$ of $\mathrm{MgCl}_{2}$ with $25 \mathrm{~g} / \mathrm{L}$ of $\mathrm{RM}$. The dosage chosen is the optimum condition for this process. The results are shown as curves (a) and (c) in Figs. 16-18. It was found that the wastes after treatment does not show any characteristic dye peaks in the wavelength range from 190 to $900 \mathrm{~nm}$. The result suggests that the dye in the wastes is transferred from the solution into the precipitate by coagulation, which can be easily separated from the liquid.

\subsubsection{Analysis of the precipitate formed after coagulation}

The precipitates formed by coagulating the reactive blue (KNR) waste, acid red (B) waste and direct blue $\left(B_{2} R_{L}\right)$ with $1.5 \mathrm{~mL} / \mathrm{L}$ of $\mathrm{MgCl}_{2}$ and $25 \mathrm{~g} / \mathrm{L}$ of RM are filtered, and then acidified to neutral $\mathrm{pH}$ to become solutions. The colors of neutral solutions are the same as those of the original dye wastes. The liquid is analyzed by a spectrophotometer and the results are shown in Figs. 16-18. It can be

\section{Table 4}

Calculated Freundlich and Langmuir isotherm parameters for dyes adsorption on RM.

\begin{tabular}{|c|c|c|c|c|c|c|}
\hline \multirow[t]{2}{*}{ Dyes } & \multicolumn{3}{|c|}{ Freundlich isotherm model } & \multicolumn{3}{|c|}{ Langmuir isotherm model } \\
\hline & $K_{\mathrm{f}}$ & $1 / n$ & $R^{2}$ & $Q_{\mathrm{m}}$ & $K$ & $R^{2}$ \\
\hline & & & & & & \\
\hline Acid red (B) & 2.96 & 0.18981 & 0.95804 & 8.921 & 0.043 & 0.97518 \\
\hline Direct blue $\left(B_{2} R_{L}\right)$ & 14.25 & 0.14391 & 0.97864 & 22.563 & 3.347 & 0.99204 \\
\hline
\end{tabular}

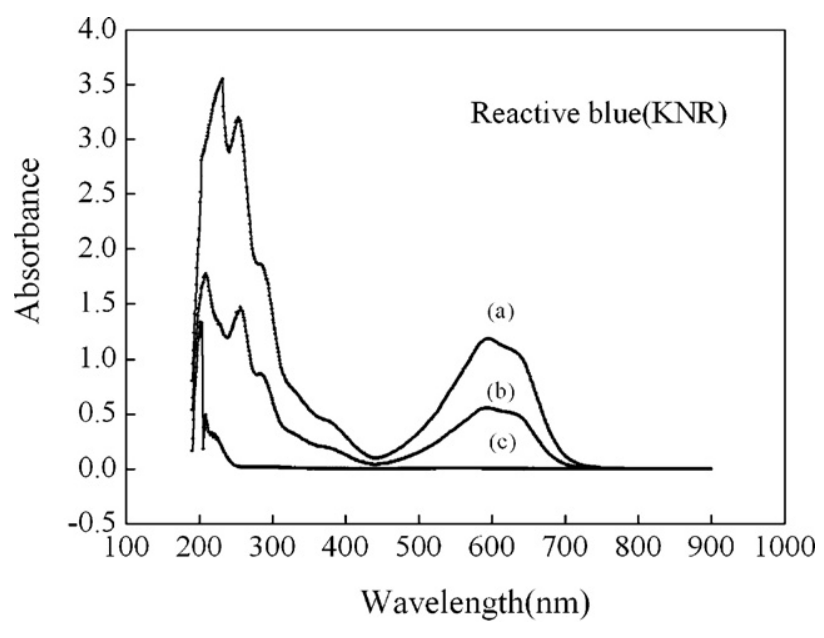

Fig. 16. The spectrogram of reactive blue (KNR).(a) The reactive blue (KNR) solution (b) the solution in which the dye deposition was turned to by acid; (c) the treated dye solution.

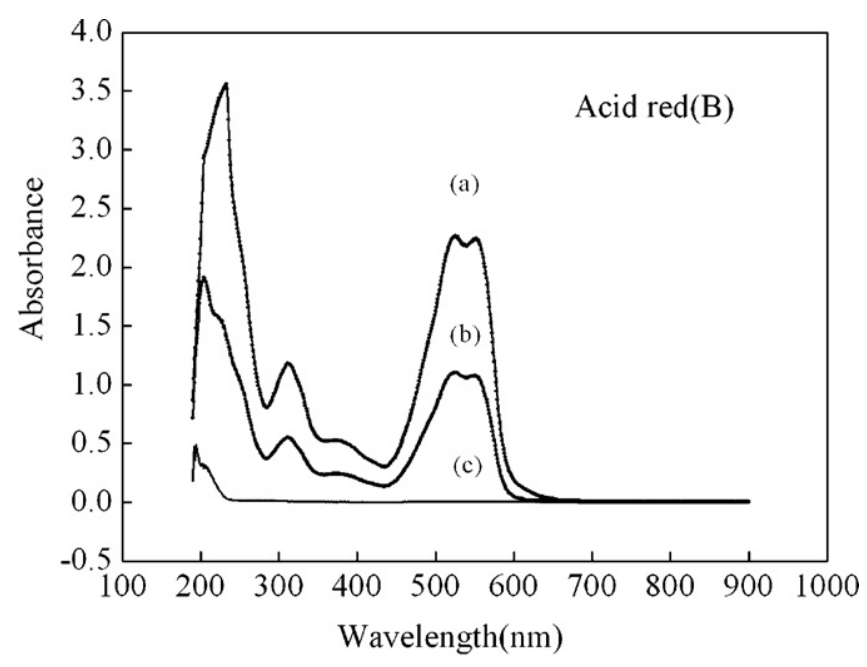

Fig. 17. The spectrogram of acid red (B). (a) The acid red (B) solution; (b) the solution in which the dye deposition was turned to by acid; (c) the treated dye solution.

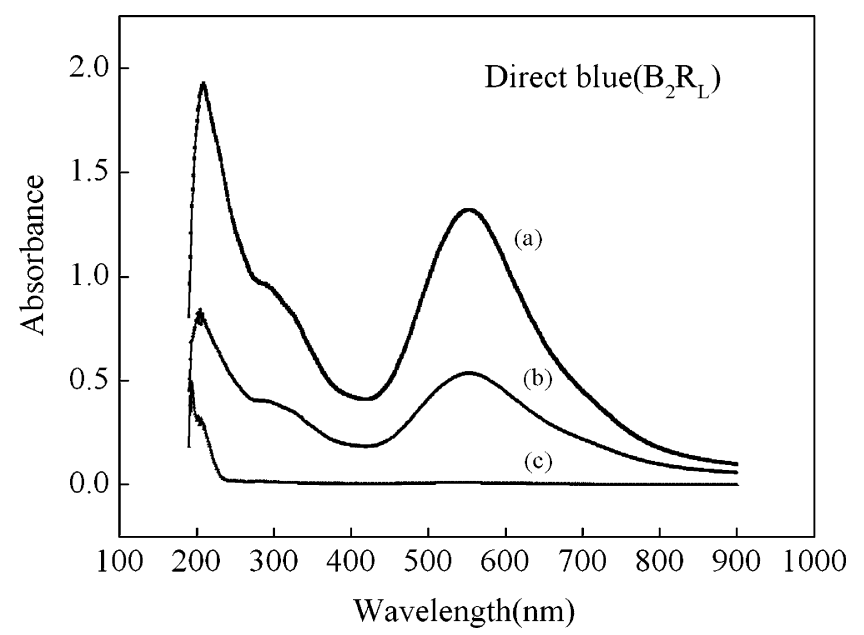

Fig. 18. The spectrogram of direct blue $\left(B_{2} R_{L}\right)$. (a) The direct blue $\left(B_{2} R_{L}\right)$ solution; (b) the solution in which the dye deposition was turned to by acid; (c) the treated dye solution. 

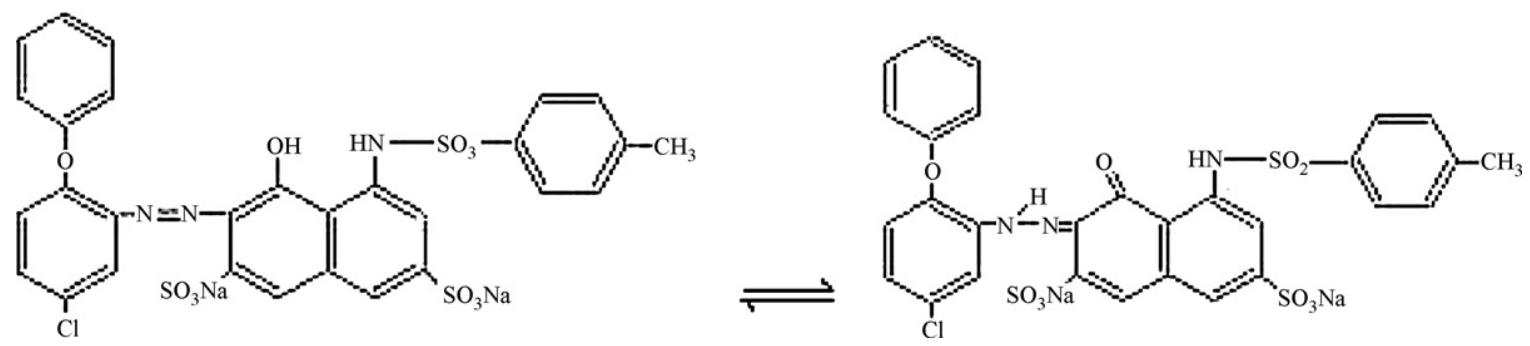

Fig. 19. Azo-hydrazone tautomerism exhibited by acid red B dye.

seen that the shapes of curves (a) and (b) appear to be completely identical. The difference in absorbance is due to the difference in the concentration of dyes between the recovered solution and the original dye wastes. The results above suggest that coagulation does not change the molecular structure of the dyes, but it transfer the dyes from the solution into the precipitate, which can easily be removed.

Furthermore, Fig. 17 shows that there are two absorbance peaks. This phenomenon indicates acid red B exists as an azo-hydrazone mixture (shown in Fig. 19), due to containing $\mathrm{OH}$ and azo group in the neighboring positions in its chemical structure [31,32]. Thus, the heterogenic system is probably formed between MRM and acid red $\mathrm{B}$ in the decolorization process. The azo-hydrazone tautomerism has a significant effect on the color removal efficiency $[33,34]$ and the hydrazone form is usually more stable [35]. This is why the color removal efficiency of acid red $B$ is relatively low and the experimental data can be described by Freudlich model well.

\subsubsection{Color removal mechanism of MRM}

According to the results given above, the color removal mechanism of MRM is probably as follows: (1) the addition of red mud can increase the $\mathrm{pH}$ value of to the dye solutions, due to the alkaline nature of red mud. In addition, red mud contains various particles with different size and shape and has specific surface area, which shows predominance as an absorbent. (2) As shown in Fig. 20, the $\mathrm{XRD}$ analysis shows that the sample is mainly composed of magnesium hydroxide. It reveals that the $\mathrm{MgCl}_{2}$ is almost transformed into $\mathrm{Mg}(\mathrm{OH})_{2}$ precipitate within the $\mathrm{pH}$ range (12-13) in the decolorization process. The structure of the precipitate provides a large adsorptive surface area and a positive electrostatic surface charge, which enables the precipitate to act as a powerful and efficient coagulant. Therefore, it is inferred that MRM removes the dyes

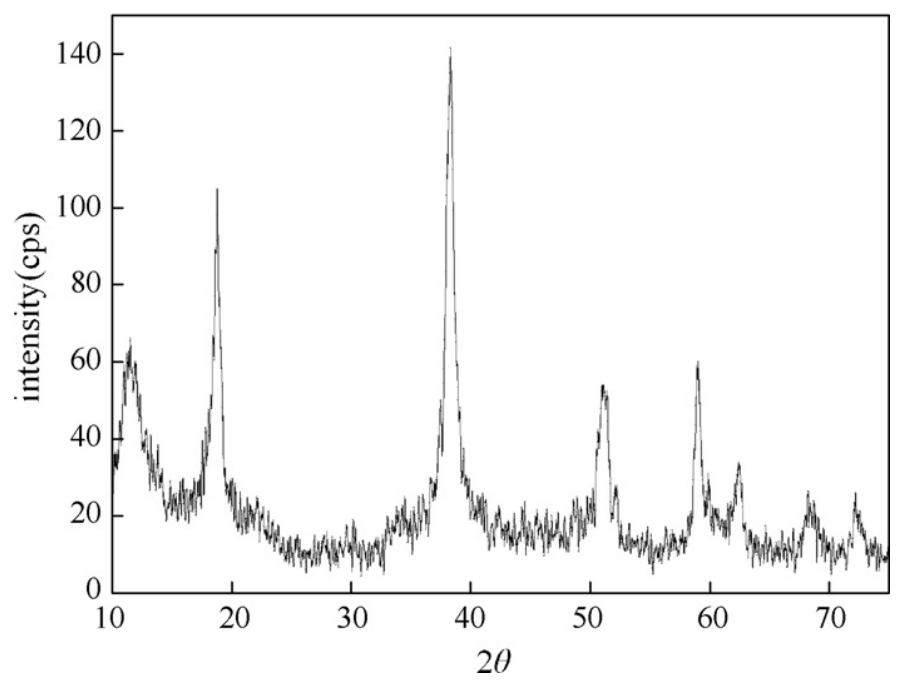

Fig. 20. XRD pattern of the precipitate. through charge neutralization and an adsorptive coagulating mechanism.

\section{Conclusions}

In this study, the combination of chemical precipitation and adsorption was investigated to improve the treatment of dye wastewaters. $\mathrm{MgCl}_{2}$ was used as the precipitator and red mud was used as the adsorbent. MRM system can be effectively used for the color removal of three dye wastewaters. Optimal precipitation and adsorption conditions were determined using dye removal efficiencies. The adsorption followed both Langmuir and Freundlich isotherms. The Langmuir adsorption capacity of the reactive blue (KNR), acid red (B) and direct blue $\left(B_{2} R_{L}\right)$ were $27.405,8.921$ and $22.563 \mathrm{mg} / \mathrm{g}$, respectively. Quantitative dye removal occurred at $\mathrm{pH}$ 12. The optimum coagulant dosages were as follows: the dosage of red mud was $25 \mathrm{~g} / \mathrm{L}$ and $\mathrm{MgCl}_{2}$ was $1.5 \mathrm{~mL} / \mathrm{L}$. The color removal efficiency of three dye solutions all can be above $98 \%$. For color removal of the reactive, acid dyes and direct dye wastewater, the combined system of $\mathrm{MgCl}_{2}$ and red mud (MRM system) is shown to be superior to $\mathrm{NaOH}, \mathrm{PAC} / \mathrm{RM}$ and PAC/NaOH. So, the MRM system is a feasible alternative to some of the more conventional forms of chemical treatment, especially for the treatment of actual textile waste with high natural $\mathrm{pH}$. Moreover, the MRM system also provides another way to make use of industrial waste RM, which can produce many benefits in terms of economy and environment.

\section{References}

[1] V. Prigione, V. Tigini, C. Pezzella, A. Anastasi, G. Sannia, G.C. Varese, Decolourisation and detoxification of textile effluents by fungal biosorption, Water Res. 42 (2008) 2911-2920.

[2] T. Robinson, G. MucMullan, R. Marchant, P. Nigam, Remediation of dyes in textile effluent: a critical review on current treatment technologies with a proposed alternative, Bioresour. Technol. 77 (2001) 247-255.

[3] N.K. Lazaridis, T.D. Karapantsios, D. Georgantas, Kinetic analysis for the removal of a reactive dye from aqueous solution onto hydrotalcite by adsorption, Water Res. 37 (2003) 3023-3033.

[4] C. Namasivayam, R.T. Yamuna, D.J.S.E. Arasi, Removal of procion orange from wastewater by adsorption on waste red mud, Sep. Sci. Technol. 37 (2002) 2412-2431.

[5] P. Janos, H. Buchtova, M. Ryznarova, Sorption of dyes from aqueous solutions onto fly ash, Water Res. 37 (2003) 4938-4944.

[6] D. Mohan, K.P. Singh, G. Singh, K. Kumar, Removal of dyes from wastewater using fly ash, a low-cost adsorbent, Ind. Eng. Chem. Res. 41 (2002) 3688-3695.

[7] K. Santhy, P. Selvapathy, Removal of reactive dyes from wastewater by adsorption on coir pith activated carbon, Bioresour. Technol. 97 (2006) 1329-1336.

[8] G.M. Walker, L.R. Weatherley, Fixed bed adsorption of acid dyes onto activated carbon, Water Res. 31 (1997) 2093-2101.

[9] S.A. Figueiredo, R.A. Boaventura, J.M. Loureiro, Color removal with natural adsorbents: modeling, simulation and experiment, Sep. Purif. Technol. 20 (2000) 129-141.

[10] O. Ozdemir, B. Armagan, M. Turan, M. Celik, Comparison of the adsorption characteristics of azo-reactive dyes on mezoporous minerals, Dyes Pigments 62 (2004) 49-60.

[11] B. Acemioglu, Adsorption of Congo red from aqueous solution onto calcium-rich fly ash, J. Colloid Interf. Sci. 274 (2004) 371-379.

[12] A. Baban, A. Yediler, D. Lienert, N. Kemerdere, A. Kettrup, Ozonation of high strength segregated effluents from a woolen textile dyeing and finishing plant, Dyes Pigments 58 (2003) 93-98. 
[13] J. Sarasa, M.P. Roche, M.P. Ormad, E. Gimeno, A. Puig J.L. Ovelleiro, Treatment of a wastewater resulting from dyes manufacturing with ozone and chemical coagulation, Water Res. 32 (1998) 2721-2727.

[14] D.J. Joo, W.S. Shin, J.H. Choi, S.J. Choi, M.C. Kim, M.H. Han, T.W. Ha, Y.H. Kim, Decolorization of reactive dyes using inorganic coagulants and synthetic polymer, Dyes Pigments 73 (2007) 59-64.

[15] T.H. Kim, C. Park, E.B. Shin, S.Y. Kim, Decolorization of disperse and reactive dye solutions using ferric chloride, Desalination 161 (2004) 49-58.

[16] Y. Zhou, Zh. Liang, Y.X. Wang, Decolorization and COD removal of secondary yeast wastewater effluents by coagulation using aluminum sulfate, Desalination 225 (2008) 301-311.

[17] B.Y. Gao, Q.Y. Yue, Y. Wang, W.Zh. Zhou, Color removal from dye-containing wastewater by magnesium chloride, J. Environ. Manage. 82 (2007) 167-172.

[18] B.H. Tan, T.T. Teng, A.K.M. Omar, Removal of dyes and industrial dye wastes by magnesium chloride, Water Res. 34 (2000) 597-601.

[19] J.F. Judkins, J.J.S. Hornsby, Color removal from textile dye waste using magnesium carbonate, J. Water Pollut. Control. Federation 50 (1978) 2446-2456.

[20] M.Y. Liao, S.J. Randtke, Predicting the removal of soluble organic contaminants by lime softening, Water Res. 20 (1986) 27-35.

[21] A.K. Jain, V.K. Gupta, A. Bhatnagar, Suhas, Utilization of industrial waste products as adsorbents for the removal of dyes, J. Hazard. Mater. B 101 (2003) 31-42.

[22] S. Kumar, R. Kumar, A. Bandopadhyay, Innovative methodologies for the utilization of wastes from metallurgical and allied industries, Resour. Conserv. Recycl. 48 (2006) 301-314

[23] C. Namasivayam, D.J.S.E. Arasi, Removal of Congo red from wastewater by adsorption onto waste red mud, Chemosphere 34 (1997) 401-417.

[24] B.Y. Gao, Q.W. Yue, Q.Y. Yue, Q.M. Zhao, Color removal from wastewater containing dye by chemical oxidation and coagulation, Res. Environ. Sci. 12 (1999) 5-9 (in Chinese).
[25] J. Leentvaar, M. Rebhun, Effect of magnesium and calcium precipitation on coagulation-flocculation with lime, Water Res. 16 (1982) 655-663.

[26] S.B. Wang, H.M. Ang, M.O. Tadé, Novel applications of red mud as coagulant, adsorbent and catalyst for environmentally benign processes, Chemosphere 72 (2008) 1621-1635.

[27] S.B. Wang, Y. Boyjoo, A. Choueib, Z.H. Zhu, Removal of dyes from aqueous solution using fly ash and red mud, Water Res. 39 (2005) 129-138.

[28] É. Poulin, J.F. Blais, G. Mercier, Transformation of red mud from aluminium industry into a coagulant for wastewater treatment, Hydrometallurgy 92 (2008) 16-25.

[29] V. Orescanin, K. Nad, L. Mikelic, N. Mikulic, S. Lulic, Utilization of bauxite slag for the purification of industrial wastewaters, Process Saf. Environ. Prot. 84 (2006) 265-269.

[30] G.P. Song, D.S. Cao, Y.H. Wang, Color removal from reactive dye-containing wastewater, Environ. Chem. 5 (1986) 25-29 (in Chinese).

[31] L. Wojnarovits, E. Takacs, Irradiation treatment of azo dye containing wastewater: an overview, Radiat. Phys. Chem. 77 (2008) 225-244.

[32] C.C. Hsueh, B.Y. Chen, Exploring effects of chemical structure on azo dye decolorization characteristics by Pseudomonas luteola, J. Hazard. Mater. 154 (2008) 703-710.

[33] C.I. Pearce, J.R. Lloyd, J.T. Guthrie, The removal of colour from textile wastewater using whole bacterial cells: a review, Dyes Pigments 58 (2003) 179-196.

[34] M.I. Beydilli, S.G. Pavlostathis, W.C. Tincher, Biological decolorization of the azo dye reactive Red 2 under various oxidation-reduction conditions, Water Environ. Res. 72 (2000) 698-705.

[35] C. Bauer, P. Jacques, A. Kalt, Investigation of the interaction between a sulfonated azo dye (AO7) and a $\mathrm{TiO}_{2}$ surface, Chem. Phys. Lett. 307 (1999) 397-406. 